\title{
Emigração de quadros, formação superior e desenvolvimento: o caso de Moçambique
}

Ana Bénard da Costa *

Resumo: A formação superior, a fuga de cérebros e o desenvolvimento constituem os temas centrais deste artigo centrado em Moçambique. Estes temas são abordados sob diferentes ângulos, de forma a captar quer as principais linhas teóricas que actualmente informam os estudos sobre essas temáticas, quer a complexidade da realidade social e das estratégias dos actores que a vivem. Desta forma apresenta-se, inicialmente, o estado da arte em relação à problemática da fuga de cérebros, relacionando-a com o aumento da mobilidade e da concorrência internacional de, e por, estudantes universitários. Conclui-se esta parte com um breve apontamento sobre aquilo que desta problemática se aferiu em relação a Moçambique. Seguidamente, e tendo por base histórias de vida de moçambicanos com formação superior que são agentes de desenvolvimento no seu país de origem, abordam-se questôes que se prendem com as identidades familiares desses quadros e com os critérios de legitimação das elites em Moçambique, relacionando este último aspecto com as problemáticas do desenvolvimento e do ensino superior.

Palavras-chave: fuga de cérebros; desenvolvimento; ensino superior; Moçambique.

Skilled migration, higher education and development: the Mozambique case

\begin{abstract}
Higher education, brain drain and development are the main subjects of this article focused on Mozambique. They are addressed from different perspectives in order to capture the main lines that currently inform theoretical studies regarding these issues, as well as the complexity of social reality and social actors' strategies. First, the author presents the state of the art of the brain drain issue, relating it to increased mobility and international competition for university students and among them. This part of the text is concluded with some brief notes regarding information collected in Mozambique. Based on life stories of Mozambicans with university degrees and who are also development agents in their own country, the second part of this article addresses topics on these people's family identities and the criteria for the legitimacy of Mozambique's elites, relating this aspect to development and higher education.
\end{abstract}

Key words: brain drain; development; higher education; Mozambique.

* Centro de Estudos Africanos, Instituto Superior de Ciências do Trabalho e da Empresa (ISCTE), Lisboa, Portugal. anabenardg@gmail.com 
Introdução

Analisando o curriculum de muitos dos quadros moçambicanos com formação superior que vivem e trabalham actualmente em Moçambique, é possível constatar que muitos deles se licenciaram ou obtiveram diplomas de pós-graduação (mestrados e doutoramentos) em universidades estrangeiras. A diversidade de países em que esses quadros se formaram espelha a história das opçôes ideológicas da Frente de Libertação de Moçambique (Frelimo) desde o período colonial até a actualidade. Numa primeira fase, muitos dos estudantes adquiriram a sua formação nos países socialistas: União Soviética, República Democrática da Alemanha, Cuba ou China, mas a partir dos inícios dos anos 1990 após a queda do muro de Berlim e com as alteraçôes políticas que culminaram na realização de eleições e na viragem do país para uma economia de mercado - essa formação realizou-se, sobretudo, nos países ocidentais: África do Sul, Brasil, Portugal, Reino Unido, Estados Unidos, Austrália, foram os destinos mencionados pelos informantes. Existem mesmo casos onde a formação se realizou numa primeira fase num país socialista e posteriormente foi realizada uma pós-graduação num país ocidental.

A formação superior, a fuga de cérebros e o desenvolvimento constituem os temas centrais deste artigo centrado em Moçambique. Estes temas são abordados sob diferentes ângulos, de forma a captar quer as principais linhas teóricas que actualmente informam os estudos sobre estas temáticas, quer a complexidade da realidade social e das estratégias dos actores que a vivem. Desta forma apresenta-se, inicialmente, o estado da arte em relação à problemática da fuga de cérebros, relacionando-a com o aumento da mobilidade e da concorrência internacional de, e por, estudantes universitários. Conclui-se esta parte com um breve apontamento sobre aquilo que deste assunto se aferiu em relação a Moçambique.

Seguidamente, e tendo por base histórias de vida de moçambicanos com formação superior que são agentes de desenvolvimento no seu país de origem, abordam-se questões que se prendem com as identidades familiares desses quadros e com os critérios de legitimação das elites em Moçambique, relacionando este último aspecto com as problemáticas do desenvolvimento e do ensino superior.

\section{Fuga de cérebros e desenvolvimento}

Quais são efectivamente os efeitos da fuga de cérebros sobre os países de partida? Esta questão tem sido objecto de diversos estudos desde a década de 60 do século passado. Nesses anos, e com poucas excepções (Berry; Soligo, 
1969), a ênfase era colocada nos benefícios que esse tipo de migrações trazia para a economia mundial (Grubel; Scott, 1966; Adams, 1968). Na década seguinte, essas conclusões foram criticadas e salientaram-se os efeitos negativos da fuga de cérebros para os países de origem. Argumentava-se que esse tipo de migrações contribuía para acentuar as disparidades entre os países ricos e pobres (Bhagwati; Hamada, 1974; 1975; Bhagwati; Rodriguez, 1975; Rodriguez, 1975; McCulloch; Yellen, 1977). Essa visão pessimista começou a ser alterada em meados dos anos 1990 quando começaram a ressurgir estudos a destacar os efeitos positivos da fuga de cérebros ${ }^{1}$. Os autores referem que esse tipo de migrações tem um impacto directo na formação do capital humano nos países de origem (Mountford, 1997; Stark et al., 1997; Vidal, 1998; Beine et al., 2001). Num trabalho recente, Michel Beine, Fréderic Docquier e Hillel Rapoport (2008, p.632) escrevem: "Descobrimos que a duplicação das taxas de emigração de quadros induzia a um aumento de cinco por cento na formação de capital humano entre a população nativa (residentes e emigrantes)". Estes autores apontam também o facto de este tipo de migração ter efeitos distributivos (remessas, regresso de emigrantes com qualificaçôes adicionais adquiridas no estrangeiro, criação de redes de cientistas e empresariais) que têm estado ausentes do debate político em torno dessa temática. (2008, p.648).

Actualmente muitos autores e organizações internacionais partilham essa visão optimista. Por exemplo, num recente livro organizado por Andrés Solimano, (2008, p.4) os argumentos que acima referimos são de novo mencionados. Nesse trabalho é utilizada a expressão brain circulation, com o argumento de que esse tipo de migrações implica cada vez menos viagens sem retorno de quadros qualificados dos países pobres para os países ricos e mais viagens de "ida e volta" (ou multi-direccionais) de indivíduos com talento, tais como estudantes, profissionais, peritos em tecnologias de informação, empresários, trabalhadores culturais e outros, que respondem às novas oportunidades que a globalização da economia mundial lhes oferece em diferentes cidades e países. (2008, p.3).

Na literatura produzida por economistas sobre esta temática também sobressai esta visão optimista. Através de modelos teóricos exploram os "vários canais através dos quais os países em desenvolvimento podem obter ganhos sociais da fuga de cérebros". (Solimo, 2008, p.4).

Esta visão aparece numa época em que a concorrência internacional por recursos humanos qualificados está a aumentar. E tal não é certamente uma

1. Esta visão optimista começa a ser partilhada pelas agências internacionais de desenvolvimento no início do presente século (PNUD, 2001; World Bank, 2002). 
coincidência. Esta concorrência tanto resulta do imput que em termos de desenvolvimento estes emigrantes trazem para os países onde vão trabalhar, como surge na sequência dos problemas económicos derivados das quebras demográficas em muitos dos países da $\mathrm{OCDE}^{2}$.

No estudo acima citado (Solimano, 2008) há, contudo, um número relativamente limitado de referências à África Subsaariana (a África do Sul é a excepção). Para além do impacto negativo que a emigração de quadros ligados ao sector da saúde implica para os países dessa região, onde existe grande incidência de doenças como o HIVISIDA e a malária, pouco mais é referenciado ${ }^{3}$. Num livro que pretende tratar da problemática da emigração de quadros em escala mundial, esta falta de referências a uma região onde se calcula que $30 \%$ dos quadros qualificados trabalhem no estrangeiro e que, por ano, cerca de 20.000 profissionais especializados, cientistas, académicos e investigadores deixem o continente, esta lacuna só se pode compreender se assumirmos que o propósito dos autores seja, sobretudo, demonstrar os impactos positivos deste tipo de migrações. Em suma, pode-se por isso concluir que, para os autores desse estudo, os efeitos positivos da fuga de cérebros não se fazem sentir na África Subsaariana.

Outros autores têm, no entanto, opiniōes diferentes sobre esse assunto. Easterly e Nyarko (2008) referem que os efeitos positivos se fazem sentir no nível das famílias dos emigrantes que se beneficiam mais (com as remessas e outros bens) do que são prejudicados pela fuga de cérebros. De acordo com os cálculos desses autores, o valor das remessas suplanta os custos da educação dos quadros que saem do país de origem (2008, p.3). E concluem, nesse seu estudo, que a fuga de cérebros tem efeitos positivos para os países africanos.

Em relação a Moçambique não se dispõe de dados concretos que permitam quaisquer conclusões sobre esse assunto; no entanto, estão disponíveis em espaços públicos de debate ( mídia e blogues) algumas opiniōes que importa mencionar.

Actualmente, e de acordo com informações disponibilizadas no site do Governo Moçambicano (http://www.govnet.gov.mz), existem 800 bolseiros moçambicanos a estudar em Universidades no estrangeiro (mas o número de moçambicanos a estudar no estrangeiro é certamente muito superior).

Em relação ao retorno desses estudantes a Moçambique após a sua formação, os únicos dados disponíveis provêm de um estudo do Banco Mundial, de

2. Por exemplo, essa concorrência é elevada entre as universidades europeias, que todos os anos têm menos estudantes dos seus países e necessitam preencher as vagas com estudantes provenientes de outras regiões do mundo.

3. Este assunto é analisado por vários autores. Ver, por exemplo, Delanyo Dovlo, Alok Bhargava and Frédéric Docquier, 2008, entre outros. 
2006. Neste refere-se que " $45 \%$ dos moçambicanos com formação universitária residem em países estrangeiros” (Özden; Schiff, 2006, p.176).

Se pensarmos que apenas uma reduzida percentagem da população moçambicana tem cursos superiores, mesmo que essa percentagem tenha aumentado significativamente nos últimos anos - de 0,27 (por mil habitantes), em 1990, para 0,96, em 2002 (MESCT, 2003, p.32) -, esta fuga de cérebros é significativa. No entanto, esta não é a opinião do Ministro da Educação de Moçambique, que afirmou em declarações recentes à imprensa o seguinte:

A fuga de quadros moçambicanos para diversos cantos do mundo à procura de melhores condiçôes de vida e de trabalho deixou de constituir problema para o nosso país, uma vez que internamente Moçambique já possui não só cérebros qualificados, como a qualidade de trabalho que se oferece melhorou muito. Este pronunciamento foi feito há dias em Maputo pelo Ministro da Educação e Cultura, Aires Ali, no decurso da palestra subordinada ao tema "Papel do Ensino Superior no Desenvolvimento de África”. (Sitoe, 2008).

Essa informação, como bem nota o sociólogo moçambicano Patrício Langa (2008a) num comentário com o título sugestivo "Falar sem dizer nada: sobre a "fuga de cérebros"?" que colocou no seu blogue, não é fundamentada por nenhum estudo e contradiz outras informações, segundo as quais:

Hoje, em Moçambique, o número de Instituições de Ensino Superior é de 23 entre Públicas (11) e Privadas (12). O número de estudantes do Ensino Superior ascende hoje a 28.000, com cerca de 1.389 docentes a tempo inteiro em todas Instituições de Ensino Superior [...]. Há poucos anos, a oferta de vagas era menor que a demanda, as instituiçôes não necessitavam de se preocupar com a optimização do uso de recursos e de ofertas de cursos com saída imediata para o mercado do trabalho [...] (Tomás, 2008).

Em suma, o aumento das instituições de ensino superior em Moçambique não se traduz, de forma automática, numa diminuição do número de moçambicanos que estudam no exterior e, sobretudo, não implica uma diminuição da chamada "fuga de cérebros", sejam estes "cérebros" formados em Moçambique ou no estrangeiro.

A "fuga de cérebros" é um fenómeno complexo e com múltiplas causas. Se muitas se prendem à situação de desenvolvimento em que o país se encontra (em termos de empregos e níveis salariais, por exemplo), outras se relacionam com a qualidade do trabalho que aí podem ou não realizar. Outras, ainda, 
prendem-se, como já se mencionou, com a concorrência internacional em termos de captação de recursos humanos qualificados para as universidades e para o mercado de trabalho onde se inserem as próprias agências de desenvolvimento internacionais e nacionais.

\section{Agentes de desenvolvimento, elites e formação superior}

Todos os agentes de desenvolvimento moçambicanos, com responsabilidades de chefia, contactados ao longo da investigação em que este artigo parcialmente se baseia (quadros de ONGs nacionais ou de agências internacionais de desenvolvimento), pertencem à elite ${ }^{4}$ económica e académica do país, possuindo, a grande maioria, uma situação de destaque em termos económicos, sociais e profissionais, sendo a sua posição actual na sociedade moçambicana resultado de estratégias de ascensão social delineadas há várias geraçôes ${ }^{5}$. Muitos desses quadros têm graus académicos de nível superior obtidos em universidades no estrangeiro (mestrados e doutoramentos nos Estados Unidos, Austrália, África do Sul e Europa).

Evidentes beneficiários do desenvolvimento do qual são simultaneamente agentes e representantes, expoentes da modernidade moçambicana, circulando em diferentes setores de poder político e económico nacionais e internacionais, como gerem estes quadros as suas relações com as suas memórias, com o seu património cultural e a sua identidade moçambicana, étnica ou familiar?

4. $\quad$ significado que aqui se atribui ao termo elites é lato e consideramos na esteira de Carola Lentz e Andrea Behrends, que pertencem a elites os indivíduos "que ocupam posições de liderança em várias esferas (políticas, económicas, culturais intelectuais) nas quais participam regularmente e decisivamente nos processos de decisão." (2004, p.4).

5. A investigação empírica foi realizada em Portugal e em Moçambique entre 2004 e 2007. Em Portugal realizaram-se histórias de vida e de família de vinte estudantes moçambicanos (o que implicou cerca de quatro entrevistas não directivas a cada um destes estudantes) e foram entrevistados responsáveis de instituições que, de alguma forma, relacionavam-se com estes estudantes ou com os estudantes africanos em Portugal (instituições governamentais portuguesas, embaixada de Moçambique, Universidades e gabinetes de apoio, associações de estudantes e núcleos de associações, câmaras de comércio e associações culturais e recreativas). $\bigcirc$ trabalho de campo em Maputo incidiu sobre quatro das famílias dos estudantes contactados em Portugal e mais 23 famílias escolhidas de acordo com critérios que pudessem dar conta de alguma diversidade de situações sociais, económicas e culturais. Para além das entrevistas e histórias de vida, esta investigação utiliza informações recolhidas em blogues da autoria de quadros moçambicanos. Nesses blogues circulam textos sobre os mais diversos assuntos e que se relacionam com a investigação. Através deles foi possível ter acesso a um certo tipo de discursos que reflectem quer o pensamento dos autores sobre os diversos temas que são abordados - e aqui o leque é variadíssimo -, quer a imagem que os autores têm de si próprios, dos seus conterrâneos e, de uma forma geral, da sociedade moçambicana da actualidade.

Pro-Posiçōes, Campinas, v. 20, n. 1 (58), p. 127-145, jan./abr. 2009 
A compreensão dessas questôes implicou uma abordagem diacrónica da história da família desses quadros ao longo das três últimas gerações, enquadrada por uma análise das transformações políticas, económicas e sociais que durante essas décadas ocorreram em Moçambique. Décadas de transformaçôes profundas - do colonialismo (nas suas diferentes fases) ao socialismo, passando por guerras e terminando, na actualidade, num liberalismo preso nas malhas e nas contradições das ideologias da cooperação para o desenvolvimento - que marcaram de forma determinante (mas diversa) os comportamentos de todos os moçambicanos.

Não é altura para aprofundar essas questões desenvolvidas noutros artigos (Costa, 2007a, 2007b); apenas refiro que todo esse complexo e continuado processo de mudanças culturais, sociais, políticas e económicas teve óbvias implicaçôes nas estratégias individuais e familiares destes actores. Estratégias, estas, que articulam de forma complexa as múltiplas dimensões que estruturam a família (nos níveis material, afectivo, simbólico, identitário e de valores) e em que a modernidade e a tradição se cruzam, entrelaçam-se e, por vezes, fundemse tanto no nível das práticas como no nível das representações sociais e ideológicas em que estas se fundamentam.

Exemplificando, transcrevem-se aqui excertos de uma conversa com um quadro moçambicano sobre a sua família:

Somos seis irmãos, um falecido. Três cá (Maputo) e dois lá (Tete, em casa dos pais). Os mais velhos são todos licenciados, os outros são mais novos, ainda são estudantes. Um já está na universidade, o outro vai entrar. Não vivem comigo, cada qual governa-se na sua casa. Umé casado, o outro coloquei-o no lare está lá bem, estuda na UEM. Não é só para estar num ambiente de estudante, acho que uma familia nuclear é melhor sozinha. Se tivermos alternativas para irmos colocando os nossos familiares em locais para crescereme tornarem-se maduros, o melhor éseguir este caminho e crescer. Cada um deve viver sozinho. Ele viveu comigo seis anos, mas não era possivel por todas as razóes e somos grandes amigos. Agora tem a sua independência. (L.M., quadro sênior de uma empresa de consultoria, entrevista realizada a 5 de agosto de 2005)

Essa concepção de família espelhada neste último período e que articula solidariedades e entreajudas entre os diferentes membros que têm a sua raiz nos sistemas de parentesco ditos tradicionais ${ }^{6}$ com concepçôes idealizadas da

6. Lembro que, por exemplo, entre os tsongas, os primos paralelos são referenciados pelo mesmo termo que os irmãos e ainda hoje isso acontece, mesmo quando os informantes se expressam em português. Esta equivalência de termos não traduz necessariamente uma equivalência entre graus de parentesco e não permite igualmente depreender correspondências entre as relações 
"modernidade" que privilegiam a família nuclear e o individualismo foram mencionadas por muitos informantes. E é notório como no nível do discurso valorizam, de forma evidente, as formas e as relaçôes que consideram como paradigma da modernidade, ainda que muitas vezes nas suas práticas prevaleçam as regras, obrigações e normas que têm a sua raiz nos modelos tradicionais. Estes modelos tradicionais continuam na actualidade a constituir referentes fundamentais dos comportamentos e das atitudes destes quadros nacionais e das estratégias através dos quais moldam e constroem as suas vidas. Como refere o informante no discurso que abaixo se transcreve: a "voz do mais velho é a mais importante, nem que acreditemos que não é a mais certa”.

Hoje a classe média, digamos, a classe moçambicana dos profissionais, vive um misto de vida profissional ocidental e uma vida tradicional africana. As nossas obrigaçôes tradicionais mantêm-se com a familia. Continuamos a respeitar a autoridade do "papá", que é voz do mais velho, é a mais importante, nem que acreditemos que não é a mais certa, mas que ela é importante é, e é importante ouvir, e é importante seguir as recomendaçôes. Nós continuamos a dar apoio, continuamos sentindo-nos responsáveis pelos outros que não têm ou precisam de apoio [...] Ainda há pouco tive de ser padrinho de um lobolo de pessoas que são universitários, mas todo aquele ritual de pedir a mão da moça continuou exactamente $o$ mesmo. Portanto, éum misto, e essa pessoa em sua casa tem computador com Internet, Tv a cabo e viaja e tem cartão de crédito. Evive esta vida que é interessante, que é uma vida profissional ocidental com condimentos africanos. Nós somos pessoas, talvez as mais letradas, somos a maior fonte de inspiração e referência, somos as mais solicitadas a padrinhos, a conselheiros, mesmo que o nosso casamento seja um desastre, todos os casados que estão melhor vêm-nos pedir conselhos". (G. L., quadro numa empresa de microcrédito, entrevista realizada a 1 de agosto de 2005)

Se é verdade que a clarificação dos processos de mudança sociais e culturais em famílias moçambicanas implica uma análise diacrónica das transformações nas estruturas e nas relaçôes familiares ao longo de, pelo menos, três geraçôes e que estas últimas só se podem entender se as relacionarmos com aspectos macroestruturais que marcaram o século XX e o início deste século em Moçambique, não é menos verdade que todos esses aspectos restem incompreensíveis se não os enquadramos nas diferentes conjunturas internacionais que

estabelecidas entre irmãos e primos moçambicanos e irmãos e primos de contextos culturais com sistemas de parentesco diverso (como seja o caso português). (cf. Costa, 2007c, p. II ; Geffray, 2000, p. 23). 
influenciaram de forma determinante a história deste país; lembro aqui, por exemplo, o colonialismo e a Guerra Fria.

$\mathrm{Na}$ impossibilidade de abordar essa relação histórica neste texto (cf. Costa 2007c; Maylin, 1995; Abrahamson; Nilsson, 1995), limito aqui a reflexão à análise das alteraçôes nos critérios de legitimação das elites moçambicanas, entendendo que é nesse grupo social que se inserem os principais agentes de desenvolvimento nacionais com formação superior. Essas alterações ocorridas, sobretudo após meados dos anos 80 do século passado implicaram a paulatina substituição do critério até então prevalecente - responsabilidades na luta anticolonial - por outro critério ligado à formação superior. A compreensão das estreitas relações entre essa gradual alteração nos critérios de legitimação das elites detentoras do poder em Moçambique e a crescente dependência desse país da Ajuda ao Desenvolvimento permitem clarificar algumas das contradiçōes e dos impasses no processo de desenvolvimento desse país e, simultaneamente, esclarecer a forma como os quadros nacionais - agentes desse desenvolvimento - vivem e autopercepcionam o desenvolvimento do seu país e as transformações que esse processo induz no nível das suas estruturas e relaçôes familiares. A necessidade de encontrar novas maneiras de legitimação de poder (quer internamente quer exteriormente) para além das formas que lhes advinham de um passado de líderes ${ }^{7}$ da luta anticolonial, aliada a outros factores que se relacionam com a opção pela continuidade dos ideais de civilização, desenvolvimento e modernidade, levou a que desde o início da independência (e no período das lutas coloniais) houvesse uma consciência da necessidade de formação de quadros. Mas, durante essa fase socialista (até finais dos anos 1980), o acesso a lugares de poder não se fazia por via da formação avançada. Os dirigentes políticos desse país mantinham os diferentes quadros, que não pertenciam ao seu núcleo duro, na sua dependência directa e em posiçôes de subalternidade. Isto ocorreu quer em termos políticos, quer em termos das liberdades profissionais individuais. Médicos, professores universitários, economistas, empresários e outros não tinham possibilidades de escolha relativas às suas estratégias de vida e eram obrigados a seguir orientaçôes superiores em termos da forma como exerciam (ou não exerciam) a sua profissão e do local onde a exerciam. Simultaneamente, o trabalho que desenvolviam no caso de serem funcionários públi$\cos$ (a grande maioria) era remunerado segundo tabelas salariais muito limita-

7. O percurso individual dos diferentes líderes dos movimentos de libertação nacional em Moçambique é diverso, mas em muitos casos está relacionado com a posição social que as respectivas famílias ocuparam em diferentes momentos na sociedade colonial e que permitiu aos seus filhos o acesso a uma certa formação escolar que posteriormente possibilitou que se deslocassem para outros países onde continuaram os seus estudos e estabeleceram relações sociais que contribuíram para o "despertar" de uma consciência política e "nacional". 
das e centralmente definidas. No caso de trabalharem no sector privado, as actividades comerciais, empresariais, industriais ou de serviços que realizavam eram controladas por uma economia centralmente planeada.

Foi no início dos anos 90 do século passado, após as negociações do governo Moçambicano com o FMI e o Banco Mundial e a introdução do liberalismo económico e da democracia política que a formação avançada começou a se impor gradualmente como um dos critérios legitimadores das elites em Moçambique. Mas esse processo de mudança não significou, por si e necessariamente, uma renovação das elites. Parte destas foi capaz de se transformar por dentro ou de associar a si novas personagens detentoras de outros tipos de capitais simbólicos e culturais (por exemplo, formação superior, conhecimento de línguas estrangeiras, domínio de códigos "culturais" ocidentais).

Esse processo de renovação ou transformação das elites, que não é isento de contradições nem de conflitos e implicou diferentes etapas - da aproximação aos círculos de poder até a sua participação plena, e consequente substituição e redefinição dos critérios e formas de legitimação. Dependeu, e depende sempre, de múltiplos factores que se articulam de forma dinâmica, complexa e relacional em torno de, pelo menos, quatro eixos que se interrelacionam:

- a relação de poder e a posição de liderança que os membros da elite desenvolvem com os grupos sociais que lhes reconhecem/atribuem essa posição social;

- a relação de poder que se estabelece dentro das elites entre os membros mais recentes e os elementos mais antigos, e os respectivos e diferenciados critérios de legitimação;

- as relaçôes que as diferentes elites nacionais estabelecem com outro tipo de elites, de dimensão mais local ou ligadas a núcleos de poder mais direccionados (corporativo/profissional/religioso/militar);

- as relações que as diferentes elites estabelecem com os seus "pares" no nível internacional e regional.

É dentro dessa complexa teia relacional que emerge a crescente importância da educação superior como forma de estratificação social e de constituição e legitimação das elites, concorrendo e, simultaneamente, agregando-se ou associando-se a outras formas de legitimação.

A complexidade desse processo e o facto de ele se desenvolver diante dos diferentes eixos relacionais que acima referimos implica, necessariamente, o recurso a diferentes tipos de capitais (no sentido de Bourdieu) simbólicos e sociais que dificilmente se encontram reunidos num único indivíduo. Daí advém a necessidade de se manterem e desenvolverem complexas e apertadas redes de "confiança" e partilha entre os diferentes membros de uma elite e 
entre as diferentes elites. Essas redes sociais através das quais as elites se constituem, mantêm, reproduzem e, simultaneamente, renovam-se e modificam-se, coincidem em muitos casos com as redes familiares.

O prestígio que actualmente a formação avançada tem nesse país e que é significativamente reforçado nos casos em que essa formação inclui estudos pós-graduados em universidades ocidentais (contrapondo-se aqui à desvalorização que actualmente sofrem as formaçóes obtidas nos então países socialistas) não está, obviamente, dissociado das relações de proximidade que se estabeleceram, sobretudo a partir de meados dos anos 1980, entre Moçambique e os países e organizações do Norte que subsidiam o Orçamento de Estado e assistem o país por via da cooperação internacional .

Por outro lado, o prestígio que advém de a formação avançada ser obtida no exterior está relacionado com os processos de legitimação que a construção das elites nacionais necessariamente implica. Ou seja, para além do reconhecimento e prestígio interno, essa legitimação, sobretudo quando falamos de elites nacionais e não locais, também tem de ser realizada interpares e num plano internacional. E para pertencer a uma elite nacional não basta ter o reconhecimento dos outros elementos da mesma elite - que necessariamente têm de o aceitar como um dos "seus" - não basta também deter posições de poder e destaque diante do seu grupo social de pertença ou diante da restante população do país respectivo; implica, igualmente, que esse lugar social seja reconhecido por aqueles com quem, noutros países ou organizaçōes, estes actores sociais estabelecem relações de proximidade - económica, social e simbólica. Esse jogo complexo de múltiplos espelhos e reflexos tem de ser habilmente manobrado, pois todos os elementos importam e não se podem sobrepor de forma excessiva ${ }^{8}$.

A importância das organizações de Ajuda e Cooperação Internacional (Banco Mundial, FMI, Nações Unidas) e dos países doadores é significativa, estando as políticas nacionais muito dependentes de orientaçôes que emanam desses espaços e das elites que os dominam. Para que a relação funcione e as orientaçôes sejam entendidas e cumpridas, é essencial que as elites moçambicanas (os agentes de desenvolvimento nacionais) falem a mesma "linguagem técnica" dos seus interlocutores estrangeiros, aprendidas nas escolas superiores do oci-

8. Jason Sumich faz uma interessante análise das elites moçambicanas, afirmando que a legitimação destas se faz cada vez mais diante da comunidade internacional de doadores e dos organismos multilaterais e menos num plano interno. Refere o autor: "No contexto moçambicano, aparentemente, os fundos internacionais não estão a ser desviados para alimentar as redes clientelistas. Pelo contrário, assegurando a legitimidade e os fundos da comunidade internacional, a elite no poder garante um grau de liberdade, na sua relação com a população do país, consolidando as diferenças de classe entre a elite e a classe média" (2008, p. 124). 
dente. Essa necessidade de diálogo e de partilha de um mesmo código de comunicação tem-se acentuado à medida que se intensificam as relações de dependência entre Moçambique e os doadores internacionais. Por isso, o processo de criação, manutenção ou transformação das elites e dos agentes de desenvolvimento em Moçambique tem de ser analisado não só do ponto de vista das relações sociais e de poder que se desenvolvem nos múltiplos níveis no espaço nacional (e regional), mas, e simultaneamente, no quadro das relaçôes internacionais e de dependência que este país desenvolveu e desenvolve com as diferentes potências estrangeiras e organismos políticos, financeiros e económicos internacionais.

Simultaneamente, esta relação tem de ser analisada em múltiplas perspectivas:

- Em termos mais gerais e macropolíticos, o processo de criação e de manutenção dessas novas elites de tecnocratas e experts do desenvolvimento, descendentes (metaforica ou literalmente) das elites políticas da geração que lutou e conquistou a independência, é apoiado e, muitas vezes, financeiramente sustentado pelas suas congéneres ocidentais por questôes relacionadas com os mecanismos e as práticas da Ajuda Internacional ao Desenvolvimento, associadas a relações de domínio e poder. Os responsáveis dos organismos internacionais e dos países doadores necessitam ter como interlocutores locais "bons parceiros" que entendam as mensagens e as directrizes políticas, económicas e, sobretudo, metodológicas e formais que pretendem transmitir. É necessário que estas elites africanas não só dominem os códigos implícitos nos conteúdos dos discursos "desenvolvimentistas" e nas estratégias de actuação política e económica, mas, talvez mais necessário ainda, que dominem e implementem, sem grandes desvios, as diferentes metodologias de acção e execução dessas políticas e os diferentes aspectos formais em que todos esses processos se apresentam e representam (relatórios, estatísticas, planos, projecções e análises). E tudo isto também se aprende nas universidades, quer nas universidades africanas moldadas por sistemas de ensino ocidentais, quer, sobretudo, nas academias dos países do Norte.

- Em um nível mais micro, das estratégias e práticas dos diferentes actores que constituem a elite moçambicana, importa retermo-nos sobre os processos de construção individual e colectiva que são necessários para ascender ao grupo restrito que, necessariamente e por definição, constitui as elites. Esse processo é complexo porque implica, por parte dos actores sociais, a capacidade de recriar, para si e em si, as diferentes representaçôes em que o "ser elite" se traduz nos seus diferentes con- 
textos de actuação. Obriga, por exemplo, que utilizem diferentes códigos de conduta e de linguagem, maneiras de vestir, comportamentos e "poses", consoante interajam entre os seus pares nacionais, locais, regionais, internacionais. E todo este conjunto de elementos simbólicos funciona como um sistema de comunicação que aproxima ou distancia diferentes actores sociais. Mas, simultaneamente, por questóes que se relacionam com os processos de autoconstrução das identidades individuais e colectivas de "ser elite", por força da "globalização" e das imagens e representaçôes que por essa via se foram construindo e divulgando, os actores sociais que constituem este grupo necessitam de proceder a articulações relativamente coerentes entre estes diferentes pólos. E é entre esses pólos (Cohen 1981, p.8) que têm de se situar de forma a serem aceites tanto pelos diferentes grupos sociais sobre os quais exercem um papel de liderança, como pelos seus diferentes "pares".

Os processos de construção das elites são assim resultantes de aceitações e reconhecimentos múltiplos que se legitimam reciprocamente. No entanto, esses processos são dinâmicos, permanentemente questionados, modificados, avaliados e recriados (Cohen, 1981, p.230), não só em função dos diferentes contextos em que os actores sociais se situam e dos actores sociais com os quais interagem, mas também em função das suas próprias representações resultantes de memórias antigas e recentes e de experiências acumuladas.

A identificação dos actores sociais com determinadas elites e o facto de estas os reconhecerem como "um dos seus" resultam de processos complexos de aprendizagem formal e informal que se processam em diferentes níveis e que possibilitam a comunhão de um conjunto de códigos. Todo este conjunto de códigos pressupõe, para aqueles que os dominam, uma aprendizagem realizada nos diferentes contextos de socialização a que os indivíduos acedem ao longo da sua vida (Cohen, 1981).

Para o assunto que aqui analisamos - a formação superior como forma de legitimação do processo de construção e transformação das elites e dos agentes moçambicanos de desenvolvimento - um desses contextos, e que em termos de identificação nos fóruns internacionais funciona de forma privilegiada, são as academias ocidentais, onde os estudantes moçambicanos aprendem, através do convívio informal com os outros estudantes, os diferentes "códigos" sociais que lhes permitem ser reconhecidos pelos seus "pares" de outros países e, como tal, desenvolver reciprocidades que poderão constituir importantes capitais sociais nos seus processos de ascensão profissional, económica e social. Esse processo de aprendizagem é contínuo ao longo da vida desses quadros e realiza-se quer dentro dos seus países de origem, através dos diferentes momentos de convívio 
profissional e social que estabelecem com os seus colegas estrangeiros que aí residem e dentro das delegaçôes das empresas multinacionais e organizações internacionais para as quais trabalham, quer nas várias ocasiōes em que se deslocam ao estrangeiro, completando a sua formação ou participando em reunióes e grupos de trabalho. Por vezes, a sua participação nestes fóruns permitelhes a ascensão a lugares de responsabilidade nas organizaçôes multilaterais de desenvolvimento, integrando-se no restrito grupo de consultores internacionais que circulam pelos países em vias de desenvolvimento, aconselhando decisores políticos e concebendo, implementando e avaliando projectos de cooperação.

Em qualquer dos casos, esses agentes moçambicanos de desenvolvimento têm de saber gerir com equilíbrio e habilidade os diversos interesses das múltiplas redes sociais em que estão inseridos, das quais dependem e diante das quais têm obrigaçôes de vária ordem. O lugar que ocupam na sociedade moçambicana e o prestígio que auferem nas instituições internacionais de desenvolvimento têm de ser constantemente reafirmados através de complexos jogos políticos em que as demonstraçôes de eficácia profissional se associam a cedências várias diante de hierarquias e poderes exteriores à sua actividade laboral. As interferências entre esses dois "universos" com interesses muitas vezes contraditórios e divergentes são constantes. Através de várias estratégias, os diferentes actores envolvidos (agentes de desenvolvimento de organizaçōes nacionais e internacionais) tentam ultrapassar essas contradiçóes e divergências ou, pelo menos, impedir que estas bloqueiem processos em que alguns, mas não todos (basta aqui lembrar o lugar que Moçambique ocupa em termos de $\mathrm{IDH}^{9}$ ) têm a ganhar. E essas estratégias passam, nomeadamente, pela construção de hábeis relatórios onde imperam os quadros lógicos, os dados, preferencialmente quantitativos, e as facturas. Nesses relatórios expressa-se uma representação documental da realidade que é, por excelência, a "realidade do desenvolvimento".

\section{Desenvolvimento e ensino superior}

E em que é que se traduz esta "realidade do desenvolvimento" em termos do ensino superior em Moçambique?

Com a abertura do mercado universitário aos privados - e porque as universidades são, em princípio, um bom negócio (mas seria interessante saber se efectivamente o são) -, os capitais nacionais e internacionais afluíram, e as

9. O país ainda se encontra, de acordo com o Relatório do Desenvolvimento Humano do PNUD de 2007/2008, nos últimos lugares dos rankings da escala mundial em termos do IDH (I 72 em 177, tendo descido em relação ao relatório anterior, em que se situava no $168^{\circ}$ lugar para o mesmo número de 177 países). 
instituições de ensino superior privadas nasceram (muitas delas parceiras e sucursais de universidades privadas portuguesas e brasileiras). Com as directrizes das organizações internacionais de desenvolvimento e a palavra de ordem que são os "Objectivos de Desenvolvimento do Milénio (ODM)", as universidades públicas foram chamadas a desempenhar o seu papel, pois também elas devem contribuir para acabar com a pobreza absoluta ${ }^{10}$. Como? Patrício Langa responde a esta questão no seu blogue:

O debate em torno do ressurgimento do ensino técnicovocacional, que visa o combate da pobreza absoluta, recupera, portanto, um cepticismo antigo acerca da relevância do conhecimento teoria (conhecimento) em relação à prática (saber-fazer) porque se crê que a teoria está de alguma maneira distanciada da realidade, portanto, não ajuda a resolver os problemas 'práticos' da população. Esquece-se, imediatamente, que o que constitui problema 'prático' para as populaçōes não é um dado adquirido ou estabelecido pela prática (técnica), mas pelo conhecimento (teoria) (e até certo ponto pela política). As ciências sociais são, por causa dessa perversão, consideradas uma perca de tempo porque se aconchegaram na província da teoria. Desse modo elas não nos podem dizer como ou a "fazer-coisas" que ajudem a combater a (pobreza absoluta) [...] Os milhões de dólares que estão a ser investidos no ensino técnico-vocacional, portanto, não são para "saber-o-que fazer" mas para fazer! Fazer o quê? Fazer aquilo que nos dizem para fazer. Quem nos diz? Aqueles que pensam por nós. É por isso que no primeiro texto sugeri que estamos a ser "pagos para não pensar". E ao que tudo indica estamos satisfeitos (2008b, grifos do autor)

Embora o "processo de desenvolvimento" tenha permitido um aumento significativo de instituições de ensino superior e o aumento da população moçambicana com formação universitária, isso, por si só, não garante que as universidades em Moçambique tenham a capacidade de formar uma elite intelectual com aptidões para exercer uma análise crítica sobre esse mesmo processo de desenvolvimento de que ela (universidade) é um dos produtos.

$\mathrm{O}$ aumento do número de moçambicanos que freqüentam instituições de ensino superior no seu país relaciona-se, também, com as mudanças que têm ocorrido em termos das políticas de bolsas dos países doadores. Tomando como exemplo o caso de Portugal, o que tem ocorrido tem sido uma inversão das

10. Pelo menos é esta a prioridade do Reitor da Universidade Eduardo Mondlane que, numa entrevista dada ao Jornal Notícias, respondeu à seguinte pergunta: "Uma vez assumido o cargo, quais são as suas grandes prioridades?", com a resposta "Fazer com que a UEM participe mais do combate à pobreza absoluta" (Jornal Notícias, 2007). 
tendências verificadas em anos anteriores. Ou seja, diminuiu significativamente o número de bolseiros de licenciaturas em Portugal e aumentou o número de bolseiros em mestrados e doutoramentos (IPAD, 2006), e Portugal concede bolsas para estudantes moçambicanos frequentarem licenciaturas em Moçambique. E essas bolsas têm por objectivo: "Formar jovens quadros em áreas consideradas prioritárias ao desenvolvimento do respectivo país; contribuir para o desenvolvimento sustentável do ensino local; contribuir para a diminuição da fuga de cérebros" (IPAD, 2008).

Mas se Portugal tem como objectivo explícito da sua política de cooperação contribuir para diminuir a fuga de cérebros, pressupondo que esta seja negativa para o desenvolvimento dos países de origem, está a assumir algo que é discutível. Como neste artigo já se mencionou, há autores que afirmam que a fuga de cérebros tem efeitos positivos em termos do desenvolvimento dos países de origem. No entanto, por tudo aquilo que ao longo deste artigo se debateu, esta conclusão (os efeitos positivos da fuga de cérebros), como a conclusão oposta (os efeitos negativos), parece enfermar dos mesmos defeitos. Por um lado, e os próprios autores o afirmam, há problemas relacionados com a falta e com a fidelidade dos dados, com a ausência de estudos mais detalhados e de análises qualitativas que possam dar informaçôes sobre os efeitos deste tipo de migrações, ao longo do tempo e entre geraçôes. Por outro lado, as teorias centrais de desenvolvimento que orientam as estratégias das organizações internacionais, em termos das opções políticas para o ensino superior, estão demasiado presas nas teias de um mercado onde as margens de manobra são muito limitadas. E, como se referiu anteriormente, esse mercado necessita da circulação e da disponibilidade destes "cérebros" para se auto-sustentar.

\section{Conclusões}

Há uma complexidade de interesses no processo de desenvolvimento da formação superior em Moçambique que impede leituras apressadas e que exige estudos mais apurados antes de se formularem conclusôes, quer estas conclusões sejam relativas ao impacto da fuga de cérebros em Moçambique, quer recaiam sobre os efeitos que o aumento quantitativo do ensino superior terá em termos de desenvolvimento do país. Também neste artigo se avançaram algumas ideias relativas à influência que a formação no exterior poderá ter nas estratégias das elites que governam o país, mas faltam dados que incidam sobre horizontes temporais mais alargados, de forma a avançar-se com conclusões fundamentadas. Seria também importante compreender qual a relação que os quadros que optaram por viver no exterior mantêm com Moçambique, de forma a aferir do seu impacto no processo de desenvolvimento que aí decorre. 
Mas, e independentemente de todos esses estudos nos poderem revelar um dia informações que permitam responder a estas questôes, um facto impõe-se como evidente nesta análise: o ensino superior em Moçambique, como em qualquer lugar deste mundo globalizado, está subordinado ao "mercado do desenvolvimento" e àquilo que se designa, também, por "economia do conhecimento". A responsabilidade das organizações internacionais e dos países doadores na condução deste "mercado" é, como este texto o demonstra, indiscutível. Pouco poderá ser efectivamente realizado se não se alterarem as políticas por que se regem estas organizações. Estas, para além de condicionarem as cooperaçôes internacionais e as ajudas bilaterais, condicionam também as teorias e as metodologias dos estudos que se realizam nos países em desenvolvimento e que procuram compreender os efeitos dessas mesmas políticas na evolução dos sistemas de ensino que ajudaram a criar.

Será que isso é possível? Até que ponto estas organizações e esses países não são reféns das próprias políticas de desenvolvimento que implementam? Até que ponto está ou não instalado um sistema de cooperação internacional à escala mundial que, para se preservar, preserva os problemas que supostamente deveria combater? São questôes em aberto que, eventualmente, nestes tempos de mudanças rápidas terão resposta mais cedo do que agora é possível imaginar.

\section{Referências bibliográficas}

ABRAHAMSON, Hans; NILSSON, Anders. Mozambique the troubled transition: from socialist construction to free market capitalism. Londres e Nova Jersey: Zed Books, 1995. p. 285.

ADAMS, Walter A. (ed.). The brain drain. Nova Iorque: Macmillan, 1968. p. 273.

BEINE, Michel; DOCQUIER, Fréderic; RAPOPORT, Hillel. Brain drain and economic growth: theory and evidence. Journal of Development Economics, Amsterdam, v. 64, n. 1, p. 275-289, 2001.

BEINE, Michel; DOCQUIER, Fréderic; RAPOPORT, Hillel. Brain drain and human capital formation in developing countries: winners and losers. The Economic Journal, Reino Unido, 118, p.631-652, abril de 2008.

BEHRENDS, Andrea; LENTZ, Carola. Hard work, achievement and luck: biographical narratives of a Ghaanaian elite. In: AFRICAN STUDIES ASSOCIATION ANNUAL MEETING, 2004, New Orleans. Comunicação, New Orleans, p. 11-14, novembro de 2004.

BERRY, R. Albert; SOLIGO, Ronald. Some welfare aspects of international migration. Journal of Political Economy, Chicago v.77, n. 5, p.778-794, 1969.

BHAGWATI, Jagdish N.; HAMADA, Koichi. The brain drain international integration of markets for professionals and unemployment: a theoretical analysis. Journal of Development Economics, Amsterdam, n. 1, p.19-24, 1974. 
BHAGWATI, Jagdish N.; HAMADA, Koichi. Domestic distortions, imperfect information and the brain drain. Journal of Development Economics, Amsterdam, n. 2, p.139-153, 1975.

COHEN, Abner. The politics of elite culture. Explorations in the dramaturgy of power in a modern African society. Berkeley: University of California Press, 1981.

COSTA, Ana Bénard. Dinâmicas de mudança social em famílias moçambicanas. In: FELICIANO, José Fialho; STATTER, Guilherme (Org.). Empresários e empreendorismo em África: experiências, reflexôes e perspectivas. Lisboa: Centro de Estudos Africanos (CEA), ISCTE. 2007a, (no prelo).

COSTA, Ana Bénard. Os quadros superiores, os empresários e as suas famílias: análise de processos de mudança social e cultural em Moçambique. Caderno de Estudos Africanos, n.11/ 12, dezembro 2006/junho 2007, p. 237-254, 2007 b.

COSTA, Ana Bénard. O preço da sombra: sobrevivência e reprodução social entre famílias de Maputo. Lisboa: Livros Horizonte, 2007c. p.167.

EASTERLY, William; Nyarko, Yaw. Is the brain drain good for Africa? Brookings GlobalEconomy and Development Working Paper, n. 19, Social in Science Research Network, março 2008. Disponível em: $<$ http://papers.ssrn.com/sol3/papers.cfm?abstract_id=1121853 $>$. Acedido a $1 / 8 / 08$.

GEFFRAY, Christian. Nempai nem mãe. Lisboa: Caminho, 2000.

GRUBEL, Herbert; SCOTT, Anthony. The international flow of human capital. American Economic Review, Pittsburgh, n. 56, p.268-274, maio 1966.

IPAD, Estratégia da Cooperação Portuguesa - Operacionalização, 2006, <http:// www.ipad.mne.gov.pt/index.php?option=com_content\&task=view\&id=388\&Itemid=321> Acedido a 26 de dezembro de 2006.

JORNAL NOTICIAS. 9 de março de 2007. Maputo, Moçambique.

LANGA, Patrício. Falar sem dizer nada: sobre a "fuga de cérebros". Blogue: Olhar Sociológico, 21 de maio de 2008. Disponível em: <http://circulodesociologia.blogspot.com/2008/05/ falar-sem-dizer-nada-sobre-fuga-de.html>. Acedido a 23/set./08. 2008a.

LANGA, Patrício. Pelo "retorno" do conhecimento.[3]. O ensino técnico-vocacional. Blogue: Olhar Sociológico, 19 de maio de 2008. Disponível em: <http:// circulodesociologia.blogspot.com/2008/05/falar-sem-dizer-nada-sobre-fuga-de.html>. Acedido a 23/set./08. 2008b.

LANGA, Patrício. Passar ou chumbar [2]. Blogue: Olhar Sociológico, 5 de agosto de 2008. Disponível em: <http://circulodesociologia.blogspot.com/search?q>. Acedido a 23/09/08, 2008c.

McCULLOCH, Rachel; YELLEN, Janet L. Factor mobility, regional development, and the distribution of income. Journal of Political Economy. University of Chicago Press, v. 85, n.1, p.79-96, fevereiro de 1977.

MCTES. Ministério do Ensino Superior, Ciência e'Tecnologia. Indicadores de Ciência e Tecnologia 
em Moçambique, 2002-2003. Portal do Governo de Moçambique, setembro de 2008. Disponível em: <http:/www.govnet.gov.mz/Informacao/ciencia_e_tecnologia/Informacao/ ciencia_e_tecnologia/indcadores_c_t $>$. Acedido a 21/set./08.

MOUNTFORD, Andrew. Can a brain drain be good for growth in the source economy? Journal of Development Economics, Amsterdam, v. 53, n. 2, p. 287-303, agosto de 1997.

NEWIT, Maylin. A History of Mozambique. Londres: Hurst \& Company, 1995, p. 679.

SITOE, Rogério. Fuga de cérebros deixou de constituir problema. Noticias, Maputo, 21 de maio de 2008. Disponível em: <http://www.jornalnoticias.co.mz/pls/notimz2/getxml/pt/ contentx/173176>. Acedido a 29/set./08.

PNUD. Relatório de Desenvolvimento Humano 2001. Disponível em: <http:// www.undp.org/hdro/indicators.html>. Acedido a 21/set./08. (citado em nota de rodapé)

RODRIGUEZ, Carlos Alfredo. Brain drain and economic growth: a dynamic model. Journal of Development Economics, Elsevier, Amsterdam, v. 2, n.3, p. 223-247, setembro de 1975.

SOLIMANO, Andrés. Globalizing, talent and human capital: implications for developing countries. Proceedings Volume, Annual World Bank Conference on Development Economics (ABCDE) for Europe, The World Bank, 2004. Disponível em <http:// www.andressolimano.com/articles/migration/migration.html>.

SOLIMANO, Andrés (Ed.). The international mobility of talent types, causes, and development impact. Oxford: Oxford University Press, 2008. p.352.

STARK, Oded; HELMENSTEIN, Christian; PRSKAWETZ, Alexia. A brain gain with a brain drain. Economics Letters, Amsterdam, v. 55, p. 227-234, 1997.

TOMÁS, Celestino Vaz. Estratégias de comunicação e marketing no contexto do mercado de ensino superior alargado (Regional). CONGRESSO BRASIL-MOÇAMBIQUE, 1. 2 de junho de 2008. Disponível em: <http://mocambiquebrasil.blogspot.com/2008/jun./prof-celestinovaz-toms.html $>$. Acedido a $01 /$ set./08.

OZDEN, Caglar; SCHIFF, Maurice (Ed.). International migration, remittances, and the brain drain. New York: Palgrave Macmillan and World Bank, 2006. 274 p.

SUMICH, Jason. Politics after the time of hunger in Mozambique: a critique of neo-patrimonial interpretation of African elites. Journal of Southern African Sudies, UK, 34, p.111-125, março de 2008.

VIDAL, Jean-Pierre. The effect of emigration on human capital formation. Journal of Population Economics, Bonn, v.11, n.4, p. 589-600, 1998.

WORLD BANK. Constructing knowledge societies: new challenges for tertiary education. Washington: The World Bank, 2002.

Recebido em 15 de julho de 2008 e aprovado em 26 de setembro de 2008. 